\title{
Discussing the Coloration Mechanism of Luodian Jade from Guizhou
}

\author{
Lei Wang1, Jinhui Lin², Taiping Ye1,3, Jing Tan1,3, Bing Wang1, Lin Yang1,2,3* \\ ${ }^{1}$ Guiyang Supervision Testing Center for Mineral Resources, Ministry of Land and Resources, Guiyang, China \\ ${ }^{2}$ Chengdu University of Technology, Chengdu, China \\ ${ }^{3}$ Engineering Technology Innovation Center of Mineral Resources Explorations in Bedrock Zones, Ministry of Natural Resources, \\ Guiyang, China \\ Email: $* 346819266 @ q q . c o m$
}

How to cite this paper: Wang, L., Lin, J.H., Ye, T.P., Tan, J., Wang, B. and Yang, L. (2020) Discussing the Coloration Mechanism of Luodian Jade from Guizhou. Open Access Library Journal, 7: e6364.

https://doi.org/10.4236/oalib.1106364

Received: April 26, 2020

Accepted: May 17, 2020

Published: May 20, 2020

Copyright $\odot 2020$ by author(s) and Open Access Library Inc.

This work is licensed under the Creative Commons Attribution International License (CC BY 4.0).

http://creativecommons.org/licenses/by/4.0/

\begin{abstract}
In this paper, we have discussed the coloration mechanism based on visible absorption spectra testing by selecting three typical samples of Luodian jade with white, pallor and cyan. The attribution analysis of absorption spectra showed that absorption of Luodian jade in visible light mainly includes charge transfer spectrum of $\mathrm{Fe}^{2+} \rightarrow \mathrm{Ti}^{4+}($ at $490 \mathrm{~nm}-500 \mathrm{~nm})$ and $\mathrm{Fe}^{2+} \rightarrow \mathrm{Fe}^{3+}$ (at $523 \mathrm{~nm}-536 \mathrm{~nm}, 646 \mathrm{~nm}-657 \mathrm{~nm}$ ), electron transition ${ }^{6} \mathrm{~A}_{1} \rightarrow{ }^{4} \mathrm{~T}_{2}\left({ }^{4} \mathrm{G}\right)$ of $\mathrm{Fe}^{3+}($ at $615 \mathrm{~nm}-632 \mathrm{~nm}, 685 \mathrm{~nm}-694 \mathrm{~nm})$ and ${ }^{4} \mathrm{~T}_{1}\left({ }^{4} \mathrm{G}\right) \rightarrow{ }^{6} \mathrm{~A}_{1}\left({ }^{6} \mathrm{~S}\right)$ of $\mathrm{Mn}^{2+}$ electron transition (at $549 \mathrm{~nm}-560 \mathrm{~nm}$ ). The color of Luodian Jade is the mixed color of complementary color caused by light-absorbing at these frequencies; moreover, different frequency absorption intensity determines the purity and brightness of color. At the same time, The results also confirmed that iron ions play an important role in the coloring mechanism especially with cyan color samples.
\end{abstract}

\section{Subject Areas}

Material Experiment, Metal Material

\section{Keywords}

Guizhou, Luodian Jade, Absorption Spectra, Coloration Mechanism

\section{Introduction}

As to the origin of nephrite color, it is generally agreed that the cyan is in direct proportion to the content of $\mathrm{Fe}^{2+}$, and the green is related to $\mathrm{Cr}, \mathrm{Ni}$, Co and other trace elements. Li Wen-wen et al. [1] and $\mathrm{Na}$ Bao-cheng et al. [2] considered 
that the color of Hetian jade was mainly determined by the total iron content in the structure by combining the visible absorption spectrum with the EPMA: the green-turquoise blue series is decided by $\mathrm{Fe}^{2+}$ and yellow-red-brown red series is namely by $\mathrm{Fe}^{3+}$, and in the meantime, trace amounts of $\mathrm{Cr}, \mathrm{Mn}$, etc., are also a factor to color in Hetian jade; the yellow-green characteristic of Longxi jade in Sichuan province is caused by two charge transfers in the form of $\mathrm{O}^{2-} \rightarrow \mathrm{Fe}^{3+}$ and $\mathrm{Fe}^{2+} \rightarrow \mathrm{Fe}^{3+}$, and the spin-forbidden transition of $\mathrm{Fe}^{2+}$ (possibly $\mathrm{Mn}^{2+}$ and $\mathrm{Fe}^{3+}$ ) also has some influence [3]. Qian Xiang-li et al. [4] analyzed five colors (gray, light green, grey green, dark green and brown) of nephrite-cat-eye in Sichuan province by EMAP and XRD and concluded that the Fe and trace Cr contents in the color origin structure were determined. White, light yellow, green, gray-green to yellow-green in Hualien nephrite is the result of the increasing content of $\mathrm{Fe}^{2+}[5]$. The study on the coloration mechanism of nephrite from Qinghai province also shows that $\mathrm{Fe}^{2+}$ is directly related to the origin of color [6]. Chen Tu-hua et al. [7] believed that the color of Hetian jade and Canadian nephrite was caused by the actinolitization in tremolite. Wilkins C.J. et al. [8] confirmed that the cause of nephrite color from New Zealand was directly related to the content of total iron in its composition by studying the infrared spectrum, visible absorption spectrum and Mössbauer spectrum. The color of Australian nephrite is mainly caused by the isomorphism substitution between $\mathrm{Cr}$ and $\mathrm{Fe}$ and $\mathrm{Mg}$ [9].

Generally, the study of the nephrite's coloration mechanism is mostly based on that occurs in basic-ultrabasic deposit. Luodian jade, which is related to the contact metamorphism between basite and carbonatite, is a new genetic type of nephrite and completely different from other discovered nephrite deposits. As a kind of nephrite resource, it is mainly distributed in the south of Luodian county and Wangmo county in Guizhou province; its mineral composition, structure and other physical characteristics are similar to those of Hetian jade. Moreover, the differences in chemical composition and material composition of the white, cyan and cyan series in Luodian jade result in some differences in the basic characteristics of jadeology. Chemical analysis results of Luodian jade show that the chemical composition of Luodian jade contains some transition metals, which incompletely filled d electron orbit, such as $\mathrm{Mg}, \mathrm{Fe}, \mathrm{Mn}, \mathrm{Ti}$, etc. [10]. Based on the mineral physics theory, however, after the electron located in the split orbitals absorbed light irradiation energy would cause its transition to a higher energy state from lower energy state, so the mineral color is a kind of complementary colour that some frequency of visible light is absorbed selectively by its internal electron transition [11]. Accordingly, we selected some samples (Photo 1) with different color to discuss the coloring mechanism of Luodian jade, which is based on the perspective of mineral physics theory, by testing UV-VIS absorption spectra, so as to more clearly explain the mechanism of the transition metal in its color genesis, at the same time, the research results to enrich the content of the basic theoretical research about Luodian jade. 


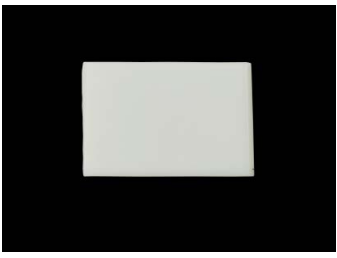

(a)

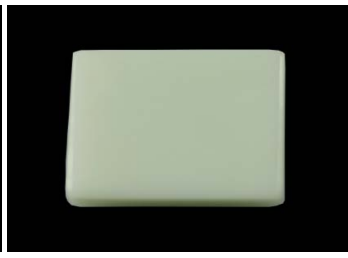

(b)

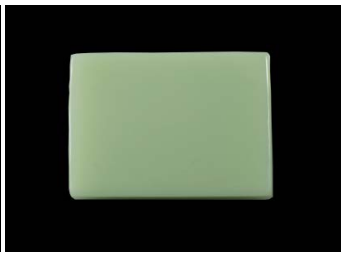

(c)

Photo 1. Samples (from (a) to (c): white, pallor and cyan).

\section{Samples and Testing}

Generally, Luodian jade's color can be divided into three types including white, pallor (bluish white) and cyan, and make three samples contains of each one into rock section to testing absorption spectra at the $350-750 \mathrm{~nm}$ wavelength by using QDI302 micro spectrophotometer. All tests are completed in the Guiyang Supervision Testing Center for Mineral Resources, Ministry of Land and Resources (MLR).

The test results as shown in Figure 1. According to Figure 1 that all samples are not absorption spectra while frequency is less than $450 \mathrm{~nm}$, on the other hand, its absorption spectrum becoming complicated as the sample color from white change to pallor or cyan. Among them it is widespread that the absorption at $490-500 \mathrm{~nm}, 550-560 \mathrm{~nm}, 610-640 \mathrm{~nm}$, and $\pm 690 \mathrm{~nm}$ in all samples, besides, shoulder absorption is also spread at $523-533 \mathrm{~nm}, 596-606 \mathrm{~nm}$ and 648 $657 \mathrm{~nm}$ in samples, appear at $511 \mathrm{~nm}$ and $584 \mathrm{~nm}$ only in pallor sample (Table 1).

\section{Spectra Attribute Classification}

The spectral characteristics of mineral are determined by the interaction between mineral electrons and crystal field along with molecular vibration. According to the theory that the absorption frequency of transition energy, which can be calculated as a electronic transition of $\mathrm{Fe}^{3+}$ when ${ }^{6} \mathrm{~A}_{1 \mathrm{~g}} \rightarrow{ }^{4} \mathrm{~T}_{2}(\mathrm{G})$ and ${ }^{6} \mathrm{~A}_{1 \mathrm{~g}} \rightarrow$ ${ }^{4} \mathrm{~T}_{1}(\mathrm{G})$ in the octahedral crystal field, are $680 \mathrm{~nm}\left(14,702 \mathrm{~cm}^{-1}\right)$ and $14,702 \mathrm{~nm}$ $\left(9950 \mathrm{~cm}^{-1}\right)$ respectively. Whenever, that belongs to spin forbidden transition when $\mathrm{Fe}^{3+}$ as in form of isomorphism to displacement $\mathrm{Al}$ in $\mathrm{AlO}_{6}$ octahedral can produce three weak absorption at 430, 450 and $460 \mathrm{~nm}$ [12] [13] [14] [15].

Some researchers pointed out by different experiments that the electronic transition of $\mathrm{Fe}^{2+}$ can mainly form absorption band near $945 \mathrm{~nm}\left(10,582 \mathrm{~cm}^{-1}\right)$ while octahedral distort to trigonal field [13] [16]. As a rule, in tremolite the absorption spectrum frequency of $\mathrm{Fe}^{2+} \rightarrow \mathrm{Fe}^{3+}$ in range of $570-840 \mathrm{~nm}$ which is formed by the charge transfer [8] [17] [18] [19] [20] [21]; in another case, the charge transfer spectrum of $\mathrm{Fe}^{2+} \rightarrow \mathrm{Ti}^{4+}$ cause to absorption near to $500 \mathrm{~nm}$ $\left(18,040 \mathrm{~cm}^{-1}\right)$ [22].

In Luodian jade, that is ubiquity such as $\mathrm{Mg}^{2+}$ in octahedral sites be replaced by $\mathrm{Mn}^{2+}$ as in form of isomorphism. However, on this occasion $\mathrm{Mn}^{2+}$ with typical $\mathrm{d}^{5}$ electron configuration in case of electron transition will lead to absorption in visible light whether which is a absorption band mainly at $450 \mathrm{~nm}, 450 \mathrm{~nm}$ 
and three absorption characteristics in the region of $360-410 \mathrm{~nm}$ or to produce a relatively steep half absorption in $400-600 \mathrm{~nm}$ region.

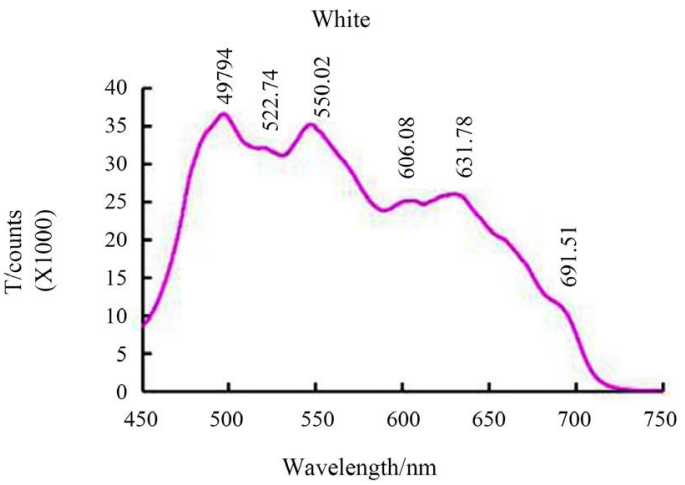

(a)

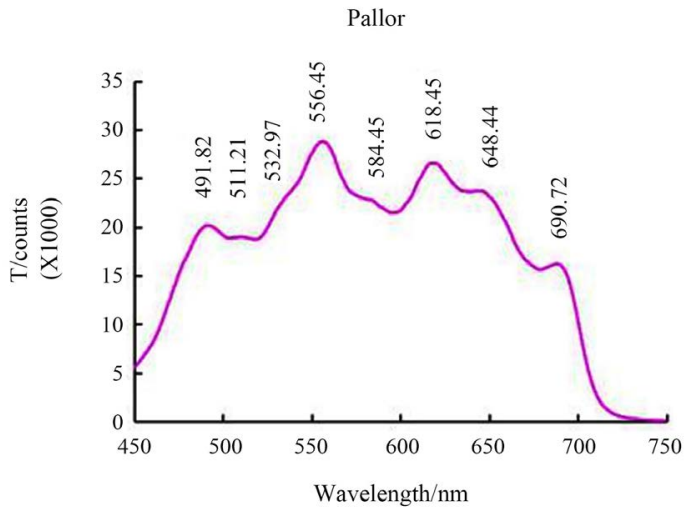

(b)

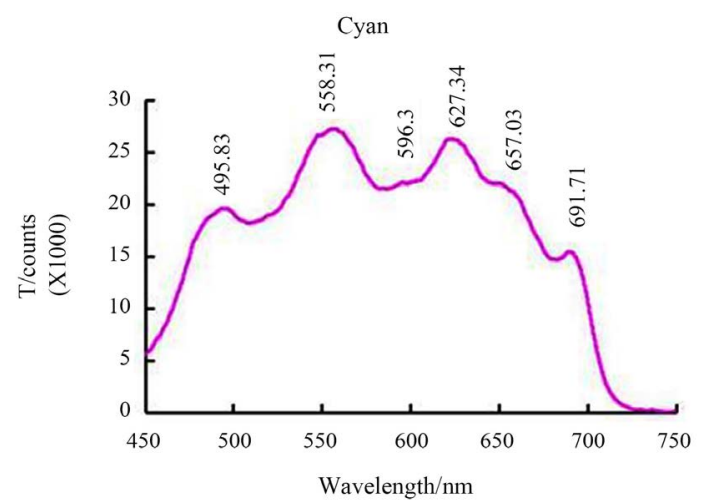

(c)

Figure 1. VIS spectra of Luodian jade (from (a) to (c): white, pallor and cyan).

Table 1. VIS spectra absorption frequency.

\begin{tabular}{cccccccccc}
\hline Samples & \multicolumn{8}{c}{ Absorption Frequency/nm } \\
\hline White & 498 & - & 523 & 550 & - & 606 & 632 & - & 692 \\
Pallor & 492 & 511 & 533 & 556 & 584 & - & 618 & 648 & 691 \\
Cyan & 494 & - & - & 558 & - & 596 & 627 & 657 & 692 \\
\hline
\end{tabular}


In addition, Yan, et al. [22], Gan, et al. [23] summarized the VIS characteristics of ions in mineral such as $\mathrm{Fe}^{2+}, \mathrm{Fe}^{3+}, \mathrm{Mn}^{3+}, \mathrm{Ti}^{4+}, \mathrm{Cr}^{3+}$ and so on (Table 2). the other achievements obtained show that there some absorption in crystal field of $\mathrm{Fe}^{3+}$ are located at $530 \mathrm{~nm}, 630 \mathrm{~nm}$ and $860 \mathrm{~nm}$ from Mars hematite $\left(\alpha-\mathrm{Fe}_{2} \mathrm{O}_{3}\right)$ [24], and on pyroxene $\mathrm{Fe}^{2+}$ which occupies $\mathrm{M}_{2}$ sites causes some absorption at $425 \mathrm{~nm}, 445 \mathrm{~nm}, 480 \mathrm{~nm}, 505 \mathrm{~nm}$ and $545 \mathrm{~nm}$ [25]. Whatever, the absorption properties of the three samples of frequency range is $450-750 \mathrm{~nm}$ are shown in Table 3 based on the integrated pre-research results. It attributable to charge transfer spectrum between in valence-state of $\mathrm{Fe}^{2+}$ and $\mathrm{Fe}^{3+}$ that optical absorption spectra of the cyan and pallor are characterized by two broad bands in range of $530-540 \mathrm{~nm}$ and $640-657 \mathrm{~nm}$, further, it may be a superposition of a few charge transfer spectrums either is $\mathrm{M}_{1}\left(\mathrm{Fe}^{2+}\right) \sim \mathrm{M}_{2}\left(\mathrm{Fe}^{3+}\right)$ and $\mathrm{M}_{1}\left(\mathrm{Fe}^{2+}\right) \sim \mathrm{M}_{2}$ $\left(\mathrm{Fe}^{2+}\right)$ or $\mathrm{M}_{3}\left(\mathrm{Fe}^{2+}\right) \sim \mathrm{M}_{1}\left(\mathrm{Fe}^{3+}\right)$. Because the samples tested contain minor amounts of $\mathrm{Cr}$ so the absorption of 492 - $498 \mathrm{~nm}$ cannot be ruled out spin forbidden transition of $\mathrm{Cr}^{3+}$.

\section{Coloration Mechanism}

In fact, each of the frequency or wavelength of visible light corresponds to one color (Table 4). According to the different scale and strength of the three primary colors red, green and blue, which wavelength is $700 \mathrm{~nm}, 546.1 \mathrm{~nm}$ and $435.8 \mathrm{~nm}$ respectively, can produce all kinds of change color in nature.

As indicated in Table 5, the mainly color after absorbing visible light frequency Luodian jade of white color is in the range of the three primary colors, when three kinds of color red, blue and green mixed up with equal proportion and intensity which color is white and belongs to the charge transfer of $\mathrm{Fe}^{2+}$ and $\mathrm{Fe}^{3+}$ in white sample at $523 \mathrm{~nm}$ and $608 \mathrm{~nm}$ also into this color range, when the proportion and intensity of these three kinds of color is inconformity then would form white-grey color, for this reason, we can concluded that Luodian jade of white color is mainly due to the absorption of this type; besides above the absorption of that it also has absorption at $627 \mathrm{~nm}$ to $657 \mathrm{~nm}$ in cyan Luodian jade, the intensity of the color of this kind of sample becomes to larger after to absorb visible light which frequency is greater than $540 \mathrm{~nm}$, on the whole, whose color is mainly present blue or green and made blue-green to be gave priority to increase, the blue-green enhanced mixes the green after being absorbed at $685 \mathrm{~nm}$

Table 2. VIS spectra of some ions.

\begin{tabular}{cc}
\hline Ions & VIS absorption frequency/nm \\
\hline $\mathrm{Fe}^{2+}$ & $550,510,450,430$ \\
$\mathrm{Fe}^{3+}$ & $700,520,490,450,400$ \\
$\mathrm{Mn}^{2+}$ & $550,450,410,370,340$ \\
$\mathrm{Ti}^{4+}$ & $640,600,550,450$ \\
$\mathrm{Cr}^{3+}$ & $700,550,400$ \\
\hline
\end{tabular}


Table 3. The location and identification of VIS.

\begin{tabular}{cccc}
\hline \multirow{2}{*}{ Attribute } & \multicolumn{3}{c}{ Samples/Frequency/nm } \\
\cline { 2 - 4 } & White & Pallor & Cyan \\
\hline $\mathrm{Fe}^{2+} \rightarrow \mathrm{Ti}^{4+}$ (charge transfer) & 498 & 492 & 494 \\
$\mathrm{Fe}^{3+}:{ }^{6} \mathrm{~A}_{1} \rightarrow{ }^{4} \mathrm{~T}_{2}\left({ }^{4} \mathrm{G}\right)$ & 632 & 618 & 627 \\
$($ electronic transition$)$ & 692 & 691 & 692 \\
$\mathrm{Fe}^{3+}: 2\left({ }^{6} \mathrm{~A}_{1}\right) \rightarrow 2\left({ }^{4} \mathrm{~T}_{1}\left({ }^{4} \mathrm{G}\right)\right)$ & - & 511 & - \\
$($ electronic transition$)$ & & & \\
& 523 & 533 & 596 \\
$\mathrm{Fe}^{2+} \rightarrow \mathrm{Fe}^{3+}$ (charge transfer $)$ & 608 & 584 & 657 \\
$\mathrm{Mn}^{2+}:{ }^{4} \mathrm{~T}_{1}\left({ }^{4} \mathrm{G}\right) \rightarrow{ }^{6} \mathrm{~A} 1\left({ }^{6} \mathrm{~S}\right)$ & & 648 & \\
$($ electronic transition $)$ & 550 & 556 & 558 \\
\hline
\end{tabular}

Table 4. The relationship between wavelength and corresponding colors.

\begin{tabular}{cccccccc}
\hline Wavelength/nm & 400 & $425-450$ & $490-510$ & 540 & 590 & 640 & $680-$ \\
\hline Coloring & \multirow{2}{*}{ Greenish-yellow } & Orange-Yellow & Red-Rose & Purple-Blue & Blue & Blue-green Green \\
\hline
\end{tabular}

Table 5. The coloration mechanism of Luodian jade.

\begin{tabular}{|c|c|c|}
\hline Color & Coloration Mechanism & Coloring \& absorption frequency/nm \\
\hline White & $\begin{array}{l}\text { electron transition: } \mathrm{Fe}^{3+},{ }^{6} \mathrm{~A}_{1} \rightarrow{ }^{4} \mathrm{~T}_{2}\left({ }^{4} \mathrm{G}\right) \\
\mathrm{Mn}^{2+},{ }^{4} \mathrm{~T}_{1}\left({ }^{4} \mathrm{G}\right) \rightarrow{ }^{6} \mathrm{~A}_{1}\left({ }^{6} \mathrm{~S}\right) \\
\text { charge transfer: } \mathrm{Fe}^{2+} \rightarrow \mathrm{Ti}^{4+}, \mathrm{Fe}^{2+} \rightarrow \mathrm{Fe}^{3+}\end{array}$ & $\begin{array}{l}\text { Red Rose Purple: } 498,523 \\
\text { Blue } \sim \text { Blue-green } \sim \text { Green: } 550,608,632, \\
692\end{array}$ \\
\hline Pallor & $\begin{array}{l}\text { electron transition: } \mathrm{Fe}^{3+}, 2\left({ }^{6} \mathrm{~A}_{1}\right) \rightarrow 2\left({ }^{4} \mathrm{~T}_{1}\left({ }^{4} \mathrm{G}\right)\right) \\
{ }^{6} \mathrm{~A}_{1} \rightarrow{ }^{4} \mathrm{~T}_{2}\left({ }^{4} \mathrm{G}\right) \\
\mathrm{Mn}^{2+},{ }^{4} \mathrm{~T}_{1}\left({ }^{4} \mathrm{G}\right) \rightarrow{ }^{6} \mathrm{~A}_{1}\left({ }^{6} \mathrm{~S}\right) \\
\text { charge transfer: } \mathrm{Fe}^{2+} \rightarrow \mathrm{Fe}^{3+}, \mathrm{Fe}^{2+} \rightarrow \mathrm{Ti}^{4+}\end{array}$ & $\begin{array}{l}\text { Red Rose } \sim \text { Purple: } 492,511,533 \\
\text { Dark blue } \sim \text { Blue } \sim \text { Blue-green: 556, 584, } 618 \\
\text { Blue-green } \sim \text { Green: } 648,691\end{array}$ \\
\hline Cyan & $\begin{array}{l}\text { electron transition: } \mathrm{Fe}^{3+},{ }^{6} \mathrm{~A}_{1} \rightarrow{ }^{4} \mathrm{~T}_{2}\left({ }^{4} \mathrm{G}\right) \\
\mathrm{Mn}^{2+},{ }^{4} \mathrm{~T}_{1}\left({ }^{4} \mathrm{G}\right) \rightarrow{ }^{6} \mathrm{~A}_{1}\left({ }^{6} \mathrm{~S}\right) \\
\text { charge transfer: } \mathrm{Fe}^{2+} \rightarrow \mathrm{Fe}^{3+}, \mathrm{Fe}^{2+} \rightarrow \mathrm{Ti}^{4+}\end{array}$ & $\begin{array}{l}\text { Red Rose: } 494 \\
\text { Dark blue } \sim \text { Blue: } 558,596 \\
\text { Blue } \sim \text { Blue-green } \sim \text { Green: } 627,657,692\end{array}$ \\
\hline
\end{tabular}

to $694 \mathrm{~nm}$ could produces the cyan color of Luodian jade. The most prominent is what one absorption at $511 \mathrm{~nm}$ to make red rose color while bluish white jade is compared with cyan and white sample, which is the result of adding white tones to green.

\section{Conclusions}

1) The absorption of Luodian jade in visible light area mainly is the charge transfer as well by $\mathrm{Fe}^{2+} \rightarrow \mathrm{Ti}^{4+}(490 \mathrm{~nm}$ to $500 \mathrm{~nm})$ and $\mathrm{Fe}^{2+} \rightarrow \mathrm{Fe}^{3+}$ (523 nm to $608 \mathrm{~nm}, 533 \mathrm{~nm}$ to $648 \mathrm{~nm}$ and $596 \mathrm{~nm}$ to $657 \mathrm{~nm}$ ) as the electron transition inclusion ${ }^{6} \mathrm{~A}_{1} \rightarrow{ }^{4} \mathrm{~T}_{2}\left({ }^{4} \mathrm{G}\right)$ of $\mathrm{Fe}^{3+}(618 \mathrm{~nm}$ to $632 \mathrm{~nm}, 691 \mathrm{~nm}$ or $692 \mathrm{~nm})$ and ${ }^{4} \mathrm{~T}_{1}$ $\left({ }^{4} \mathrm{G}\right) \rightarrow{ }^{6} \mathrm{~A}_{1}\left({ }^{6} \mathrm{~S}\right)$ of $\mathrm{Mn}^{2+}(550 \mathrm{~nm}$ to $558 \mathrm{~nm})$.

2) Iron ion plays a very important role in the coloring Mechanism of Luodian jade especially in the cyan color samples (Tables 1-5). On the one hand it is widespread on the earth; on the other hand, it can replace $\mathrm{Mg}^{2+}$ and $\mathrm{Al}^{3+}$ in the shape of $\mathrm{Fe}^{2+}$ or $\mathrm{Fe}^{3+}$ in nature. 


\section{Acknowledgements}

Thanks to the colleagues with the help on test of UV-VIS, and this study was supported by a Guizhou Province Important Special Funded Projects of Science and Technology Grant.

\section{Foundation}

Guizhou province important special funded projects of science and technology, No. [2014] 6003.

\section{Conflicts of Interest}

The authors declare no conflicts of interest regarding the publication of this paper.

\section{References}

[1] Li, W.-W. and Wu, R.-H. (1999) Study on the Color and Chromaticity of Hetian Jade. Geochemical Bulletin of Mineral Rocks, 18, 418-422.

[2] Na, B.-C., Leng, Y.-Y. and Li, X.-H. (2008) Study on Color Elements of Neushu. Engineering of Superhard Materials, 20, 55-58.

[3] Wang, C.-Y. (1993) Geological and Physicochemical Characteristics of Longxi Neusite Deposit. Minerals and Geology, 7, 201-205.

[4] Qian, X.-L., Zhou, K.-C. and Qi, L.-J. (2005) Preliminary Study on Color Classification and Color Mechanism of Nephrite-Cat-Eye in Sichuan. China Mining Industry, 14, 73-75.

[5] Tan, L.P. and Tsui, P.C. (1978) Trace Elements and Color of the Fengtien Nephrite, Taiwan. In: A Mineralogical Study of the Fengtien Nephrite Deposits of Hualien, Taiwan, NSC Special Publication, National Science Council, Taipei, 29-41.

[6] Kong, B., Zou, J.-F. and Zheng, X.-Q. (1997) Gemological Characteristics of Nephrite from Qinghai. Mineral Geology, 11, 268-271.

[7] Chen, T.-H. and Li, X.-H. (1992) Study on the Physical Characteristics and Composition of Main Jade. Nonmetallic Geology, No. 1, 8-14.

[8] Wilkins, C.J., Tennant, W.C., Williamson, B.E., et al. (2003) Spectroscopic and Related Evidence on the Coloring and Constitution of New Zealand Jade. American Mineralogist, 88, 1336-1344. https://doi.org/10.2138/am-2003-8-917

[9] Neusite, F.D. (1990) Foreign Non-Metallic Minerals \& Gemstones. Foreign Non-Metallic Mineras \& Gemstones, No. 2, 40-42. (In Chinese)

[10] Yang, L., Lin, J.-H., Wang, L., et al. (2012) Petrochemistry Characteristics and Genesis Significance of Luodian Jade from Guizhou. Journal of Mineralogy and Petrology, 32, 12-19.

[11] Marfunin, A.S. (1984) Introduction to Mineral Physics. Translated by Li Gaoshan, Geological Publishing House, Beijing, 55-117. (In Chinese)

[12] Marusak, L.A. and Messier, R. (1908) Optical Absorption Spectrum of Hematite $\alpha-\mathrm{Fe}_{2} \mathrm{O}_{3}$ near IR to UV. Journal of Physics and Chemistry of Solids, 41, 986-1103. https://doi.org/10.1016/0022-3697(80)90105-5

[13] Lehman, G. and Harder, H. (1970) Optical Spectra of Di- and Trivalent Iron in Corundum. American Mineralogist, 55, 98-105. 
[14] Sherman, D.M. (1987) Molecular Orbital Theory of Metal-Metal Charge Transfer Processes in Minerals I: Application to and Electron Delocalization in Mixed-Valence Iron Oxides and Silicates. Physics and Chemistry of Minerals, 14, 1121-1139. https://doi.org/10.1007/BF00309810

[15] Krebs, J.J. and Maisch, W.G. (1971) Exchange Effects in Optical Absorption Spectrum of $\mathrm{Fe}^{3+}$ in $\mathrm{Al}_{2} \mathrm{O}_{3}$. Physical Review B, 4, 757-769.

https://doi.org/10.1103/PhysRevB.4.757

[16] Anbalagan, G., Murugesan, S.K., Balakrishnan, M., et al. (2008) Structural Analysis, Optical Absorption and EPR Spectroscopic Studies on Chrysotile. Applied Clay Science, 42, 175-179. https://doi.org/10.1016/j.clay.2008.01.011

[17] Ferguson, J. and Fielding, P.E. (1972) The Origins of the Colors of Natural Yellow, Blue and Green Sapphires. Australian Journal of Chemistry, 25, 1371-1385. https://doi.org/10.1071/CH9721371

[18] Schmetzer, K. and Bank, H. (1980) Explanation of the Absorption Spectra of Natural and Synthetic Fe- and Ti-Containing Corundum. Neues Jahrbuch für Mineralogie-Abhandlungen, 139, 216-225.

[19] Mattson, M. and Rossman, G.R. (1987) Identifying Characteristics of Charge Transfer Transitions in Minerals. Physics and Chemistry of Minerals, 14, 1107-1123. https://doi.org/10.1007/BF00311152

[20] Smith, G. (1978) Evidence for Absorption by Exchange-Coupled Fe ${ }^{2+}$-Pairs in the near IR Spectra of Minerals. Physics and Chemistry of Minerals, 3, 782-795. https://doi.org/10.1007/BF00311848

[21] Cai, Y.-F., Li, X., Pan, Y.-G., et al. (2008) The Color-Causing Mechanism of $\mathrm{Mn}^{2+}$ and $\mathrm{Fe}^{3+}$ : Evidence from the Italian Cretaceous Pelagic Red Limestones. Acta Geologica Sinica, 82, 133-138.

[22] Yan, S.-X., Zhang, B., Zhao, Y.-C., et al. (2003) Summarizing the VIS-NIR Spectra of Minerals and Rocks. Remote Sensing Technology and Application, 18, 191-201.

[23] Gan, F.-P., Wang, R.-S. and Ma, A.-N. (2003) Spectral Identification Tree (SIT) for Mineral Extraction Based on Spectral Characteristic of Minerals. Earth Science Frontiers (China University of Geosciences, Beijing, China), 10, 445-454. https://doi.org/10.1117/12.466877

[24] Marra, A., Lane, M.D., Orofino, V., et al. (2011) Mid-Infrared Spectra and Optical Constants of Bulk Hematite: Comparison with Particulate Hematite Spectra. Icarus, 211, 839-848. https://doi.org/10.1016/j.icarus.2010.09.021

[25] Cloutis, E.A., Klima, R.L., Kaletzke, L., et al. (2010) The 506 nm Absorption Feature in Pyroxene Spectra: Nature and Implications for Spectroscopy-Based Studies of Pyroxene-Bearing Targets. Icarus, 207, 295-313.

https://doi.org/10.1016/j.icarus.2009.11.025 